\title{
A Network Pharmacology-Based Study on Pharmacological Activities and Mechanisms of Essential Oil in Leaves of C. Grandis 'Tomentosa'
}

Jieshu You

Guangzhou University of Chinese Medicine https://orcid.org/0000-0002-4722-412X

Sheng-cai He

Guangzhou University of Chinese Medicine

Liang Chen

Guangzhou University of Chinese Medicine

Zhen-hui Guo

Guangzhou University of Chinese Medicine

\section{Fei Gao}

Chengdu University of Traditional Chinese Medicine

\section{Ren-kai Li}

University of Hong Kong

\section{Wei-ling Qu}

Guangzhou University of Chinese Medicine

Wei Chen ( $\boldsymbol{\sigma}$ chenwei@gzucm.edu.cn )

Guangzhou University of Chinese Medicine https://orcid.org/0000-0002-9800-5760

\section{Research}

Keywords: Leaves of C. grandis 'Tomentosa', Essential oils, GC-MS/MS, Network pharmacology, Component-target-disease

Posted Date: May 17th, 2021

DOl: https://doi.org/10.21203/rs.3.rs-509976/v1

License: (c) (i) This work is licensed under a Creative Commons Attribution 4.0 International License. Read Full License 


\section{Abstract}

Background and Objective: Citrus grandis 'Tomentosa', as the fruit epicarp of $C$. grandis 'Tomentosa' or $C$. grandis (L.) Osbeck, is widely used in health food and medicine. Actually, based on our survey results, there are also rich essential oils with bioativities in leaves, but the chemical compounds in this part and relevant pharmacological activities have never been studied systematically yet. Therefore, this study was to preliminarily decipher the pharmacological activities and mechanisms of the essential oil in leaves of C. grandis 'Tomentosa' by an integrated network pharmacology approach.

Methods: Essential oil compositions from leaves of $C$. grandis 'Tomentosa' were identified using GCMS/MS. And then the targets of these oil compositions were predicted and screened from TCMSP, SwissTargetPrediction, STITCH and SEA databases. STRING database was used to construct the proteinprotein interaction networks, and the eligible protein targets were input into WebGestalt 2019 to carry out GO enrichment and KEGG pathway enrichment analysis. Based on the potential targets, disease enrichment information was obtained by TTD databases. Cytoscape software was used to construct the component-target-disease network diagrams.

Results: Finally, 61 essential oil chemical components were identified by GC-MS/MS, which correspond to 679 potential targets. Biological function analysis showed that there were 12, 19, and $12 \mathrm{GO}$ entries related to biological processes, cell components and molecular functions, respectively. 43 KEGG pathways were identified, of which the most significant categories were terpenoid backbone biosynthesis, TNF signaling pathway and leishmaniasis. The component-target-disease network diagram revealed that the essential oil compositions in leaves of $C$. grandis 'Tomentosa' could treat tumors, immune diseases, neurodegenerative diseases and respiratory diseases, which were highly related to CHRM1, PTGS2, CASP3, MAP2K1 and CDC25B.

Conclusion: This study may provide a new insight into $C$. grandis 'Tomentosa' or $C$. grandis (L.) Osbeck and may provide useful information for future utilization and development.

\section{Background}

Citri Grandis Exocarpium (Huajuhong), recorded officially in the current Chinese Pharmacopoeia (2020 edition), is the fruit epicarp of $C$. grandis 'Tomentosa' or $C$. grandis (L.) Osbeck particularly originated from Huazhou town in Guangdong province, southern China. Citri Grandis Exocarpium is a medicinal and edible food and is well known as nutritional benefits and pharmaceutical effects. It is a rich source of flavonoids, essential oil, polysaccharides, coumarins and limonoids [1-3]. Its therapeutic effects in traditional Chinese medicine include regulating qi-flowing and eliminating dampness and phlegm. Modern researches further demonstrated that Citri Grandis Exocarpium has anti-tussive, anti-oxidant, antiinflammatory, anti-microbial, anti-proliferative and anti-atherosclerotic activities [4, 5].

Fruit epicarp and whole fruit are the most commonly used parts of $C$. grandis 'Tomentosa' or $C$. grandis (L.) Osbeck, in which essential oils play an important in pharmacological effects. Essential oil is a 
concentrated hydrophobic liquid containing volatile aroma compounds usually extracted from plants. Essential oils are often used for aromatherapy to induce relaxation and proper application can effectively treat diseases [6]. Actually, based on our survey results, there are also rich essential oil in the leaves of $C$. grandis 'Tomentosa', but the chemical compounds in this part and relevant pharmacological activities have never been studied systematically yet. Due to the limited availability of reference substances, gas chromatography coupled with tandem mass spectrometry (GC-MS/MS) was applied to characterize components in this study, which have been widely accepted to be the predominant tool for the analysis of essential oil contents. It provides significant advantages for unequivocal identification and quantification of very low limits of ingredients [7]. Network pharmacology, proposed by Andrew L Hopkins [8], can build a "compound-target-disease" multilevel network to analyze the active ingredients, relevant pharmacological activities and possible molecular network mechanisms, which is highly in accordance with the connotation of holistic theory, multi-components and multi-targets of Chinese medicine [9-11].

In this study, essential oil contents in the leaves of $C$. grandis 'Tomentosa' were identified by GC-MS/MS and network pharmacology was employed to establish the compound-target-disease network to explore the potential pharmacological activities and mechanism. The results obtained will provide direct and reliable evidence for the broader research and application of $C$. grandis 'Tomentosa', which will contribute to reducing the waste of resource and bringing economic benefits.

\section{Methods}

\section{Identification of essential oil composition}

Leaves of $C$. grandis 'Tomentosa' (Fig. 7) were obtained from the genuine producing area Huazhou city and were authenticated by Professor Huan-lan Liu from Guangdong University of Chinese Medicine. $50 \mathrm{~g}$ leave pieces were extracted by Soxhlet extractor with $150 \mathrm{~mL}$ anhydrous ether for $18 \mathrm{~h}$. Then the extract was dried by anhydrous sodium sulfate, and concentrated to dryness with a termovap sample concentrator. The ether was evaporated and the volume was adjusted to $1 \mathrm{~mL}$ with $\mathrm{n}$-hexane. The sample was filtered through a $0.22 \mu \mathrm{m}$ PTFE syringe filter. The chemical composition of essential oil was determined by GC-MS/MS. GC analysis was performed on an Agilent 5977B GC-MS/MS system, equipped with an Agilent Multimode injector. The column used was a HP- $5 \mathrm{~ms}, 30 \mathrm{~m} \times 0.25 \mathrm{~mm}$ i.d., $0.25 \mu \mathrm{m}$ film thickness. The carrier gas was helium at a constant flow rate of $1.0 \mathrm{~mL} / \mathrm{min}$. The injection was conducted in splitless mode at $250^{\circ} \mathrm{C}$ for $3 \mathrm{~min}$ and the injected volume was $1 \mu \mathrm{L}$. The oven temperature program consisted in the following steps: an initial temperature of $60^{\circ} \mathrm{C}$ maintained for 3 min, heating from $60^{\circ} \mathrm{C}$ to $110^{\circ} \mathrm{C}$ at a rate of $5^{\circ} \mathrm{C} / \mathrm{min}$, and then raised to $150^{\circ} \mathrm{C}$ at a rate of $4^{\circ} \mathrm{C} / \mathrm{min}$, where the final temperature of $240^{\circ} \mathrm{C}$ was held for $5 \mathrm{~min}$. The temperature of the transfer line was $240^{\circ} \mathrm{C}$. The mass spectrometer was operated in electron ionization mode at $70 \mathrm{eV}$ and the ions were detected by a triple quadrupole mass spectrometer. Data acquisition and analyses were performed using the MassHunter Workstation software.

\section{Targets screening of essential oil composition}


The protein targets of the essential oil composition in leaves of $C$. grandis 'Tomentosa' were searched via the TCMSP (http://tcmspw.com/tcmsp.php), SwissTargetPrediction

(http://www.swisstargetprediction.ch/), STITCH (http://stitch.embl.de/), and SEA [26]

(http://sea.bkslab.org/) for each chemical component. Homo sapiens were the only species for the targets and the repetitive targets collected were removed. Then the component-target network of essential oil composition was constructed using Cytoscape software (Version 3.2.1) [27]. The network was analyzed using Cytoscape plugin CentiScaPe to calculate topological parameters, mainly including the degree, betweenness centrality, closeness centrality and average shortest path length [28]. The major ingredients and targets were represented by significant node, and the interactions were encoded by edges.

\section{Construction and analysis of PPI}

The PPI analysis was constructed by the open STRING database (https://string-db.org/cgi/input.pl), which contains information on protein/gene interactions, including verified experimental data, computational predicted data, and public text collections [29]. The targets of the essential oil composition were imported into the STRING database and the species was defined as Homo sapiens. Then only the data on PPIs with high confidence scores (scores $\geq 0.9$ ) were adopted for further analysis.

\section{Go functional and pathway enrichment analyses}

From a systematic point of view, the interaction of target proteins is more likely to participate in different biological processes and other cellular components under the cells instead of performing their functions independently [30]. In this study, the targets obtained from PPI network analysis were input into WEBbased Gene SeT AnaLysis Toolkit (WebGestalt, www. webgestalt.org) 2019 to carry out GO enrichment and KEGG pathway enrichment analysis. WebGestalt [31] supports 12 organisms, 342 gene identifiers and 155175 functional categories, and is widely used for gene set enrichment analysis. The GO and KEGG pathway enrichment analyses were carried out for the top 10 hub genes with a threshold of FDR< 0.05 .

\section{Network construction of active component-target-disease}

Diseases were obtained from TTD (http://db.idrblab.net/ttd/) [32] based on the successful and clinical trial targets via PPI network analysis. Then the component-target-disease network was constructed using Cytoscape software (Version 3.2.1).

\section{Results}

\section{Determination of essential oil composition in leaves of C. grandis 'Tomentosa'}

A total ion chromatogram obtained by GC-MS/MS for essential oil composition in leaves of $C$. grandis 'Tomentosa' was shown in Fig. 1. In total, 61 essential oil chemical components were identified and listed in Table 1. The families of detected essential oils in leaves mainly included terpenes (48.41\%) and the oxygen containing derivatives of the terpenes-alcohols (34.73), which were consistent with the previous reports, but the contents was higher than those extracted in the same method from the Citri Grandis 
Exocarpium (fruit) [12]. The major compound was $\beta$-caryophyllene (15.75\%), followed by (3R,6E)-nerolidol (12.66\%), bicyclogermacrene (10.74\%), $\beta$-citronellol (5.21\%), 1-Methyl-4-(1-methylethylidene)-2-(1methylvinyl)-1-vinylcyclohexane (4.92\%), geraniol (4.12\%) and phytol (4.03\%). 
Table 1

Major essential oil components of leaves from C. grandis 'Tomentosa'

\begin{tabular}{|c|c|c|c|c|}
\hline No. & RT(min) & Compound & $\begin{array}{l}\text { Content } \\
(\%)\end{array}$ & CAS \\
\hline 1 & 6.071 & Myrcene & 0.67 & $\begin{array}{l}123- \\
35-3\end{array}$ \\
\hline 2 & 6.780 & D-Limonene & 0.62 & $\begin{array}{l}5989- \\
27-5\end{array}$ \\
\hline 3 & 6.929 & trans- $\beta$-Ocimene & 0.79 & $\begin{array}{l}3779- \\
61-1\end{array}$ \\
\hline 4 & 7.861 & Terpinolene & 0.16 & $\begin{array}{l}586- \\
62-9\end{array}$ \\
\hline 5 & 8.048 & Linalool & 0.19 & $\begin{array}{l}78-70- \\
6\end{array}$ \\
\hline 6 & 9.059 & (R)-(+)-Citronellal & 0.23 & $\begin{array}{l}2385- \\
77-5\end{array}$ \\
\hline 7 & 9.633 & 4-Terpineol & 0.24 & $\begin{array}{l}562- \\
74-3\end{array}$ \\
\hline 8 & 10.643 & (-)-cis-Carveol & 0.22 & $\begin{array}{l}1197- \\
06-4\end{array}$ \\
\hline 9 & 10.935 & $\beta$-Citronellol & 5.21 & $\begin{array}{l}106- \\
22-9\end{array}$ \\
\hline 10 & 10.973 & Nerol & 0.91 & $\begin{array}{l}106- \\
25-2\end{array}$ \\
\hline 11 & 11.029 & Isogeraniol & 0.19 & $\begin{array}{l}5944- \\
20-7\end{array}$ \\
\hline 12 & 11.228 & Neral & 0.35 & $\begin{array}{l}106- \\
26-3\end{array}$ \\
\hline 13 & 11.641 & Geraniol & 4.12 & $\begin{array}{l}106- \\
24-1\end{array}$ \\
\hline 14 & 12.008 & Citral & 0.55 & $\begin{array}{l}141- \\
27-5\end{array}$ \\
\hline 15 & 13.953 & $\begin{array}{l}\text { 1-Methyl-4-(1-methylethylidene)-2-(1-methylvinyl)-1- } \\
\text { vinylcyclohexane }\end{array}$ & 4.92 & $\begin{array}{l}3242- \\
08-8\end{array}$ \\
\hline 16 & 14.261 & a-Cubebene & 0.37 & $\begin{array}{l}17699- \\
14-8\end{array}$ \\
\hline 17 & 14.625 & Neryl acetate & 0.44 & $\begin{array}{l}141- \\
12-8\end{array}$ \\
\hline
\end{tabular}




\begin{tabular}{|c|c|c|c|c|}
\hline No. & RT(min) & Compound & $\begin{array}{l}\text { Content } \\
(\%)\end{array}$ & CAS \\
\hline 18 & 15.009 & a-Copaene & 0.47 & $\begin{array}{l}3856- \\
25-5\end{array}$ \\
\hline 19 & 15.203 & Geranyl acetate & 0.35 & $\begin{array}{l}105- \\
87-3\end{array}$ \\
\hline 20 & 15.498 & $\beta$-Elemene & 1.65 & $\begin{array}{l}515- \\
13-9\end{array}$ \\
\hline 21 & 15.918 & Isocaryophyllene & 0.75 & $\begin{array}{l}118- \\
65-0\end{array}$ \\
\hline 22 & 16.459 & $\beta$-Caryophyllene & 15.75 & $\begin{array}{l}87-44- \\
5\end{array}$ \\
\hline 23 & 16.595 & $\beta$-Copaene & 1.83 & $\begin{array}{l}18252- \\
44-3\end{array}$ \\
\hline 24 & 16.682 & $\mathrm{Y}$-Elemene & 1.2 & $\begin{array}{l}29873- \\
99-2\end{array}$ \\
\hline 25 & 16.856 & $(+)$-Aromadenderne & 1.08 & $\begin{array}{l}489- \\
39-4\end{array}$ \\
\hline 26 & 16.962 & $\begin{array}{l}\text { Naphthalene, 1,2,3,4,4a,5,6,7-octahydro-1,4a-dimethyl-7-(1- } \\
\text { methylethenyl)-, (1S,4aR,7R)- }\end{array}$ & 0.43 & $\begin{array}{l}52026- \\
55-8\end{array}$ \\
\hline 27 & 17.189 & Geranylacetone & 1.05 & $\begin{array}{l}689- \\
67-8\end{array}$ \\
\hline 28 & 17.304 & (Z)-Caryophyllene & 4 & $\begin{array}{l}6753- \\
98-6\end{array}$ \\
\hline 29 & 17.926 & $\begin{array}{l}\text { (1R,4aR,8aS)-7-methyl-4-methylidene-1-propan-2-yl- } \\
\text { 2,3,4a,5,6,8a-hexahydro-1 H-naphthalene }\end{array}$ & 1.37 & $\begin{array}{l}30021- \\
74-0\end{array}$ \\
\hline 30 & 18.059 & (-)-Germacrene D & 1.44 & $\begin{array}{l}23986- \\
74-5\end{array}$ \\
\hline 31 & 18.183 & $\beta$-Lonone & 0.47 & $\begin{array}{l}79-77- \\
6\end{array}$ \\
\hline 32 & 18.603 & Bicyclogermacrene & 10.74 & $\begin{array}{l}24703- \\
35-3\end{array}$ \\
\hline 33 & 18.799 & a-Farnesene & 0.78 & $\begin{array}{l}502- \\
61-4\end{array}$ \\
\hline 34 & 18.986 & $(-)-y$-Cadinene & 0.5 & $\begin{array}{l}39029- \\
41-9\end{array}$ \\
\hline 35 & 19.278 & $(-)-\delta$-Cadinene & 3.06 & $\begin{array}{l}483- \\
76-1\end{array}$ \\
\hline
\end{tabular}




\begin{tabular}{|c|c|c|c|c|}
\hline No. & RT(min) & Compound & $\begin{array}{l}\text { Content } \\
\text { (\%) }\end{array}$ & CAS \\
\hline 36 & 19.489 & 1,4-Cadinadiene & 0.26 & $\begin{array}{l}29837- \\
12-5\end{array}$ \\
\hline 37 & 20.049 & Caryophyllene oxide & 0.21 & $\begin{array}{l}1139- \\
30-6\end{array}$ \\
\hline 38 & 20.179 & Germacrene B & 0.32 & $\begin{array}{l}15423- \\
57-1\end{array}$ \\
\hline 39 & 20.586 & (3R,6E)-Nerolidol & 12.66 & $\begin{array}{l}40716- \\
66-3\end{array}$ \\
\hline 40 & 20.941 & Spathulenol & 2.93 & $\begin{array}{l}6750- \\
60-3\end{array}$ \\
\hline 41 & 21.071 & Globulol & 2.58 & $\begin{array}{l}51371- \\
47-2\end{array}$ \\
\hline 42 & 21.31 & Viridiflorol & 0.75 & $\begin{array}{l}552- \\
02-3\end{array}$ \\
\hline 43 & 22.529 & Isospathulenol & 0.69 & $\begin{array}{l}88395- \\
46-4\end{array}$ \\
\hline 44 & 22.883 & Spathulenol & 0.39 & $\begin{array}{l}77171- \\
55-2\end{array}$ \\
\hline 45 & 23.042 & T-Muurolol & 0.92 & $\begin{array}{l}19912- \\
62-0\end{array}$ \\
\hline 46 & 23.182 & Torreyol & 0.24 & $\begin{array}{l}19435- \\
97-3\end{array}$ \\
\hline 47 & 23.474 & a-Cadinol & 1.54 & $\begin{array}{l}481- \\
34-5\end{array}$ \\
\hline 48 & 23.962 & Cadalin & 0.44 & $\begin{array}{l}483- \\
78-3\end{array}$ \\
\hline 49 & 24.717 & Tetradecanal & 0.23 & $\begin{array}{l}124- \\
25-4\end{array}$ \\
\hline 50 & 24.844 & Farnesol & 0.29 & $\begin{array}{l}4602- \\
84-0\end{array}$ \\
\hline 51 & 25.081 & $\begin{array}{l}\text { (1S,3aR,4R,8R,8aS)-1-Isopropyl-3a-methyl-7- } \\
\text { methylenedecahydro-4,8-epithioazulene }\end{array}$ & 0.35 & $\begin{array}{l}72445- \\
42-2\end{array}$ \\
\hline 52 & 25.146 & Farnesal & 0.21 & $\begin{array}{l}502- \\
67-0\end{array}$ \\
\hline 53 & 26.243 & Neophytadiene & 0.39 & $\begin{array}{l}504- \\
96-1\end{array}$ \\
\hline
\end{tabular}




\begin{tabular}{|lllll|}
\hline No. & RT(min) & Compound & $\begin{array}{l}\text { Content } \\
(\%)\end{array}$ & CAS \\
\hline 54 & 26.977 & Methyl palmitate & 0.52 & $\begin{array}{c}112- \\
39-0\end{array}$ \\
\hline 55 & 27.144 & Isophytol & 0.45 & $505-$ \\
& & & & $32-8$ \\
\hline 56 & 27.275 & Butyl isodecyl phthalate & 1.28 & $89-18-$ \\
\hline 57 & 27.719 & Geranyllinalool & 0.21 & $1113-$ \\
& & & & $21-9$ \\
\hline 58 & 28.201 & Methyllinolenate & 0.37 & $301-$ \\
& & & & $00-8$ \\
\hline 59 & 28.319 & Phytol & 4.03 & $150-$ \\
& & & & $86-7$ \\
\hline 60 & 30.517 & Oleamide & 0.18 & $301-$ \\
& & & & $02-0$ \\
\hline 61 & 30.93 & Bis(2-ethylhexyl) adipate & 0.22 & $103-$ \\
& & & & $23-1$ \\
\hline
\end{tabular}

\section{Potential targets of essential oil composition}

A total of 2417 potential targets of all essential oil composition for Homo. sapiens were obtained from the Traditional Chinese Medicine Systems Pharmacology Database and Analysis Platform (TCMSP), SwissTargetPrediction, STITCH and Similarity ensemble approach (SEA) databases after deleting repetitions (Supplementary file, Table S1). Figure 2 showed the component-target network of essential oil composition in leaves of $C$. grandis 'Tomentosa', which contained 679 targets. The circular nodes represent the targets of essential oil composition, and the diamond nodes represent the chemical composition of essential oil. Each edge represents the interaction between the active component and the target. Only the targets with higher values of "degree" (above two-fold of the median value), "betweenness centrality" and "closeness centrality" (above the median value), and "average shortest path length" (below the median value) were identified as the candidate targets of the essential oil composition in leaves of $C$. grandis 'Tomentosa'. Ultimately, 4 direct targets were found to be highly correlated with the essential oil composition, among which PTGS2, CHRM1, GGPS1 and MAPK14 were associated with 34, 32, 20 and 9 chemical components, respectively (Table 2). 
Table 2

The major targets of essential oil components in leaves from $C$. grandis 'Tomentosa' and its relevant topological parameters

\begin{tabular}{|lllllll|}
\hline $\begin{array}{l}\text { Uniprot } \\
\text { ID }\end{array}$ & Protein name & $\begin{array}{l}\text { Gene } \\
\text { name }\end{array}$ & Degree & $\begin{array}{l}\text { Betweenness } \\
\text { centrality }\end{array}$ & $\begin{array}{l}\text { Closeness } \\
\text { centrality }\end{array}$ & $\begin{array}{l}\text { Average } \\
\text { shortest } \\
\text { path } \\
\text { length }\end{array}$ \\
\hline P35354 & $\begin{array}{l}\text { Prostaglandin G/H } \\
\text { synthase 2 }\end{array}$ & PTGS2 & 34 & 0.033479 & 0.425274 & 2.351425 \\
\hline P11229 & $\begin{array}{l}\text { Muscarinic } \\
\text { acetylcholine receptor } \\
\text { M1 }\end{array}$ & CHRM1 & 32 & 0.035744 & 0.417564 & 2.394844 \\
\hline $\begin{array}{l}\text { Geranylgeranyl } \\
\text { Q16539 }\end{array}$ & GGPS1 & 20 & 0.017712 & 0.405168 & 2.468114 \\
\hline $\begin{array}{l}\text { synthase } \\
\text { Mitogen-activated } \\
\text { protein kinase 14 }\end{array}$ & MAPK14 & 9 & 0.013179 & 0.413812 & 2.416554 \\
\hline
\end{tabular}

\section{Construction and analysis of the PPI (protein-protein interaction) network}

The PPI network was showed in Fig. 3. The network contained 54 nodes (representing the action target) and 161 edges (representing association between a pair of action targets). Based on the calculation results from the Search Tool for the Retrieval of Interacting Genes (STRING) database, JUN and FOS were found to have the strongest combination ability and the combined score reached 0.999 . According to the PPI network diagram, MAPK14 was in the center of the targets, which could be associated with 38 proteins, followed by JUN and TNF, associating with 16 and 15 respectively.

\section{Functional enrichment analysis of target protein}

For biological process, the target proteins were mainly enriched in metabolic process, biological regulation and response to stimulus (Fig. 4A). In terms of cellular component, it was revealed that these target proteins were mainly enriched in nucleus, cytosol and membrane-enclosed lumen (Fig. 4B). For molecular function, it was uncovered that the most target protein were enriched in protein binding, ion binding and transferase activity (Fig. 4C). The enrichment analysis of the Kyoto Encyclopedia of Genes and Genomes (KEGG) pathway revealed that 43 enriched categories were identified, in which 40 most significant categories such as terpenoid backbone biosynthesis, TNF signaling pathway and leishmaniasis were shown in Fig. 5.

\section{Network construction of active component-target-disease}

Diseases achieved from Therapeutic Target Database (TTD) were shown in Table 3. These diseases could be classified as tumors, immune diseases, neurodegenerative diseases and respiratory diseases. Tumors mainly included oral cancer, solid tumor/cancer, Paget's disease, melanoma, non-small-cell lung 
cancer, neoplasm and colorectal cancer. Immune diseases included rheumatoid arthritis, inflammation, autoimmune diabetes, immune system disease and arthritis. Neurodegenerative diseases involved Alzheimer disease and cognitive impairment. Respiratory diseases mainly included asthma and chronic obstructive pulmonary disease.

Table 3

Diseases obtained from TTD based on the targets via PPI network analysis

\begin{tabular}{|c|c|c|c|}
\hline Target & Disease & Target & Disease \\
\hline TNF & $\begin{array}{l}\text { Rheumatoid arthritis; } \\
\text { Intermittent claudication }\end{array}$ & DUSP1 & Non-small-cell lung cancer \\
\hline \multirow[t]{2}{*}{ TP53 } & Oral cancer; & MAP2K1 & Solid tumour/cancer \\
\hline & Solid tumour/cancer & & \\
\hline \multirow[t]{2}{*}{ STAT3 } & Inflammation; & PTGES & Alzheimer disease; Neoplasm \\
\hline & Immune System disease & & \\
\hline PTGS2 & Pain; Arthritis & HMOX1 & Neonatal hyperbilirubinemia \\
\hline \multirow[t]{2}{*}{ MAPKAPK2 } & Inflammation; & PLA2G4A & Asthma \\
\hline & Autoimmune diabetes & & \\
\hline \multirow[t]{2}{*}{ FDPS } & Hypercalcaemia; & CDC25B & Solid tumour/cancer \\
\hline & Paget's disease & & \\
\hline IL1B & $\begin{array}{l}\text { Immune System disease; } \\
\text { Hypercalcaemia }\end{array}$ & CASP3 & Solid tumour/cancer \\
\hline CXCL8 & Melanoma; Pain & MKNK1 & $\begin{array}{l}\text { Solid tumour/cancer; Colorectal } \\
\text { cancer }\end{array}$ \\
\hline \multirow[t]{2}{*}{ ALOX5 } & Asthma; & CHRM1 & $\begin{array}{l}\text { Cognitive impairment; Chronic } \\
\text { obstructive pulmonary disease }\end{array}$ \\
\hline & Lymphatic filariasis & & \\
\hline
\end{tabular}

Active component-target-tumor network, active component-target-immune disease network, active component-target-neurodegenerative disease network and active component-target-respiratory disease network were established, respectively (Fig. 6). As shown in Fig. 6A, 9 essential oil compositions could act on CASP3, MAP2K1 and CDC25B, respectively and be associated with solid tumor/cancer. These 9 essential oil compositions were farnesol, geranyllinalool, a-Cadinol, T-Muurolol, torreyol, globulol, phytol, methyl palmitate and oleamide. Besides, butyl isodecyl phthalate and methyllinolenate could be linked to neoplasm by acting on PTGES. Tetradecanal, methyl palmitate and oleamide could be linked to Paget's disease by acting on FDPS. Linalool and $\beta$-elemene could act on TP53 and be associated with oral cancer and solid tumor/cancer. As shown in Fig. 6B, 34 essential oil compositions could act on PTGS2 and be linked to arthritis. The essential oil compositions included phytol, isophytol, farnesol, cadalin, germacrene B, caryophyllene oxide, (-)- - -cadinene, bicyclogermacrene, (-)-germacrene D, (1R,4aR,8aS)-7- 
methyl-4-methylidene-1-propan-2-yl-2,3,4a,5,6,8a-hexahydro-1 H-naphthalene, (Z)-caryophyllene, $\mathrm{Y}^{-}$ elemene, $\beta$-caryophyllene, isocaryophyllene, geranyl acetate, a-copaene, $a$-cubebene, geraniol, neral, isogeraniol, nerol, $\beta$-citronellol, terpinolene, $\mathrm{D}$-limonene, $\beta$-elemene, linalool, methyl palmitate, citral, bis(2ethylhexyl) adipate, oleamide, methyllinolenate, farnesal, (3R,6E)-nerolidol and neryl acetate. There was also an interaction among the essential oil compositions citral and methyl palmitate, the target TNF, and the disease rheumatoid arthritis. Figure $6 \mathrm{C}$ revealed that butyl isodecyl phthalate and methyllinolenate could be connected to Alzheimer disease by acting on PTGES. Besides, CHRM1 was forecasted as the major target for the treatment of cognitive impairment, of which 32 essential oil compositions (isospathulenol, spathulenol, $\beta$-lonone, a-cadinol, torreyol, T-muurolol, globulol, (-)-cis-Carveol, (R)-(+)citronellal, geranyllinalool, phytol, isophytol, cadalin, caryophyllene oxide, (-)- $\gamma$-cadinene, $(1 \mathrm{R}, 4 \mathrm{aR}, 8 \mathrm{aS})-7-$ methyl-4-methylidene-1-propan-2-yl-2,3,4a,5,6,8a-hexahydro-1 H-naphthalene, (Z)-caryophyllene, $\beta$ caryophyllene, isocaryophyllene, a-copaene, a-cubebene, neral, terpinolene, D-limonene, $\beta$-elemene, citral, butyl isodecyl phthalate, farnesal, viridiflorol, (3R,6E)-nerolidol, geranylacetone, and neryl acetate) were connected with them. As shown in Fig. 6D, 6 essential oil compositions could act on PLA2G4A and ALOX5, respectively and be associated with asthma. These 6 essential oil compositions were methyl palmitate, oleamide, farnesal, methyllinolenate, butyl isodecyl phthalate and neryl acetate. 32 essential oil compositions (isospathulenol, spathulenol, $\beta$-lonone, a-cadinol, torreyol, T-muurolol, globulol, (-)-ciscarveol, geranyllinalool, (R)-(+)-citronellal, phytol, isophytol, cadalin, caryophyllene oxide, (-)- $\gamma$-cadinene, (1R,4aR,8aS)-7-methyl-4-methylidene-1-propan-2-yl-2,3,4a,5,6,8a-hexahydro-1H-naphthalene, (Z)Caryophyllene, $\beta$-Caryophyllene, isocaryophyllene, $a$-copaene, $a$-cubebene, neral, terpinolene, $D$-limonene, $\beta$-elemene, citral, butyl isodecyl phthalate, farnesal, viridiflorol, $(3 \mathrm{R}, 6 \mathrm{E})$-nerolidol, geranylacetone and neryl acetate) were predicted as the major ingredients in leaves of $C$. grandis 'Tomentosa' for the treatment of chronic obstructive pulmonary disease, and CHRM1 was regarded as the key target.

\section{Discussion}

Traditional Chinese medicine is an important resource bank for the development of innovative new drugs. However, compound Chinese medicine has the characteristics of multiple components, multiple targets, and multiple levels, and its mechanism is wide and difficult to be elucidated, so all of these greatly limits the use and development of Chinese medicine. In recent years, combination of Chinese medicine and network pharmacology has become a research hotspot, which contributes to systematically exploring the target and synergistic effects of the components of Chinese medicine, further realizing the development and modernization of Chinese medicine.

This study was to excavate the potential targets of the essential oil in leaves of $C$. grandis 'Tomentosa', explore its pharmacological mechanism and predict its treatable diseases based on the method of network pharmacology. The results showed that a total of 61 chemical components in the essential oil had their corresponding target proteins in the TCMS, Swiss Target Prediction, STITCH and SEA database, and a total of 679 potential targets were obtained. After filter by condition, 4 direct targets were found to be highly correlated with the essential oil composition, of which were PTGS2, CHRM1, GGPS1 and MAPK14. The PPI network was successfully constructed, which contained 54 nodes and 161 edges. 
Functional enrichment analysis showed that there were 12, 19, and 12 Gene Ontology (G0) entries related to biological processes, cell components and molecular functions, respectively. A total of $43 \mathrm{KEGG}$ pathways were obtained, of which the most significant was terpenoid backbone biosynthesis. 22 diseases were achieved from TTD and they were mainly classified as tumors, immune diseases, neurodegenerative diseases and respiratory diseases.

In the KEGG pathways, several experimental and clinical evidences reveal that TNF signaling pathway, toll-like receptor signaling pathway, VEGF signaling pathway, arachidonic acid metabolism, osteoclast differentiation, MAPK signaling pathway, IL-17 signaling pathway, Th17 cell differentiation, NF-kappa B signaling pathway, GnRH signaling pathway, relaxin signaling pathway, Epstein-Barr virus infection, human cytomegalovirus infection, herpes simplex infection, NOD-like receptor signaling pathway, apoptosis and viral carcinogenesis were involved in tumors, suggesting that these pathways may be the mechanisms of the essential oil from leaves of $C$. grandis 'Tomentosa' in treating tumors. Besides, TNF signaling pathway, IL-17 signaling pathway, toll-like receptor signaling pathway, VEGF signaling pathway, inflammatory bowel disease, MAPK signaling pathway, Th17 cell differentiation, NF-kappa B signaling pathway, Th1 and Th2 cell differentiation, Epstein-Barr virus infection, T cell receptor signaling pathway, human cytomegalovirus infection, NOD-like receptor signaling pathway, human immunodeficiency virus 1 infection and apoptosis were demonstrated to have a correlation with immune diseases. In addition, the potential target proteins of the essential oil in leaves of $C$. grandis 'Tomentosa' were enriched in TNF signaling pathway, toll-like receptor signaling pathway, amyotrophic lateral sclerosis, neurotrophin signaling pathway, human cytomegalovirus infection, apoptosis, which were involved in neurodegenerative diseases. Pertussis, Th17 cell differentiation, NF-kappa B signaling pathway, influenza $A, T$ cell receptor signaling pathway, herpes simplex infection and apoptosis were involved in the signal transduction of respiratory diseases, which may also be the main mechanism of the essential oil in leaves of $C$. grandis 'Tomentosa' in treating respiratory diseases.

In these pathways, apoptosis was involved in the regulation of four diseases. Th17 cell differentiation and NF-kappa B signaling pathway were connected with 3 diseases, including tumors, immune diseases and respiratory diseases. TNF signaling pathway, toll-like receptor signaling pathway and human cytomegalovirus infection also have connection with 3 diseases, including tumors, immune diseases and neurodegenerative diseases. Cell apoptosis, sometimes called programmed cell death, is an active process of commanding mutated cells to commit suicide. Apoptosis plays an important role in the occurrence of several diseases, such as tumor/cancer, autoimmune diseases, AIDS, ischemia, and neurodegenerative diseases. It is generally believed that malignant tumors are caused by the uncontrolled growth of cells and excessive proliferation. From the perspective of cell apoptosis, it is believed that the occurrence of malignant tumors is the result of the inhibition of tumor apoptosis [13]. Autoreactive T lymphocytes and antibody-producing B lymphocytes are the main immunopathological mechanisms that cause autoimmune diseases. Under the stimulation of self-antigens, immune cells that recognize selfantigens are activated and eliminated by apoptosis [14]. However, if this mechanism is disturbed, the clearance of immune-competent cells that recognize self-antigens will be obstructed. Cohen observed that $L p r$ and $g / d$ mice developed lymphadenopathy and splenomegaly in an age-dependent manner, by 
accumulating activated T lymphocytes and B lymphocytes [15]. Alzheimer's disease is an irreversible degenerative neurological disease, which is caused by the acceleration of nerve cell apoptosis. Studies found that presenilin-1 (PS1) and presenilin-2 (PS2) mutations lead to familial Alzheimer's disease [16]. Meanwhile, presenilin was demonstrated to be involved in the regulation of neuronal apoptosis [17]. Apoptosis is also relevant to the pathogenesis of different respiratory diseases. Asthma has been demonstrated to be associated with a defective activation of T-cell apoptosis through FAS death receptor [18]. Reactive oxygen species induced cell apoptosis have also been known to play a factor in the pathogenesis of acute respiratory distress syndrome [19].

In the network of component-target-disease, component-target-tumor network, component-target-immune disease network, component-target-neurodegenerative disease network and component-target-respiratory disease network were established. In which, CHRM1 was regarded as the main target becasue 32 essential oil compositions could act on CHRM1 and further be highly associated with cognitive impairment and chronic obstructive pulmonary disease. Pharmacological evidence suggests that cholinergic receptors are vital members of the cholinergic system, in which CHRM1 plays an important role in cognitive processes, hippocampal synaptic plasticity and neuronal excitability [20]. Some studies also found that CHRM1 was associated with bronchoconstriction of the airways, asthma, nicotine dependence and chronic obstructive pulmonary disease [21-23]. Farnesol was regarded as the most active essential oil composition in leaves of $C$. grandis 'Tomentosa', which was involved in solid tumor/cancer, arthritis, cognitive impairment, asthma and chronic obstructive pulmonary disease. Farnesol, a natural terpene, is frequently found in essential oils [24]. A systematic review summarized that farnesol possessed broad pharmacological activities, including antimicrobial effect, preventing and treating cancer, promoting neuroprotective and behavioral effects, cardioprotective and hypotensive effects, antioxidant and anti-inflammatory properties [25].

\section{Conclusion}

In summary, this study was to study the pharmacological activity and mechanism of the essential oil in leaves of $C$. grandis 'Tomentosa' based on network pharmacology. The specific chemical components of the essential oil were identified by GC-MS/MS, so the prediction accuracy is relatively high. The results revealed that the essential oil in leaves of $C$. grandis 'Tomentosa' had the potential to treat tumors, immune diseases, neurodegenerative diseases and respiratory diseases by multi-pathways and multitargets. In which, the most promising evidence was that farnesol may treat cognitive impairment and chronic obstructive pulmonary disease by regulating apoptosis via targeting CHRM1. However, further pharmacological experimental verification is needed.

The essential oils of leaves in $C$. grandis 'Tomentosa' have not been studied before. This study may provide a new insight into $C$. grandis 'Tomentosa' or $C$. grandis (L.) Osbeck and may provide useful information for future utilization and development.

\section{Abbreviations}


GC-MS/MS: Gas chromatography coupled with tandem mass spectrometry;

TCMSP: Traditional Chinese Medicine Systems Pharmacology Database and Analysis Platform;

SEA: Similarity ensemble approach; GO: Gene Ontology

STRING: Search Tool for the Retrieval of Interacting Genes;

WebGestalt: WEB-based Gene SeT AnaLysis Toolkit;

KEGG: Kyoto Encyclopedia of Genes and Genomes;

\section{Declarations}

\section{Ethics approval and consent to participate}

Not applicable.

\section{Consent for publication}

Not applicable.

\section{Availability of data and materials}

All data generated or analysed during this study are included in this published article [and its supplementary information files]

\section{Competing interests}

The authors declare that they have no competing interests.

\section{Funding}

The study was supported by Grant of National Natural Science Foundation (81904272).

\section{Authors' contributions}

YJS and CW: study concept and design; acquisition of data; analysis and interpretation of data; drafting of the manuscript; critical revision of the manuscript for important intellectual content; statistical analysis.

HSC, CL and GZH: GC-MS/MS experiment; analysis and interpretation of data.

GF, LRK and QWL: material support; analysis and interpretation of data; critical revision of the manuscript.

All authors read and approved the final manuscript. 
Acknowledgements

Not applicable.

\section{References}

1. Chen Z, Lin L. [Study on coumarin compounds from Exocarpium Citri Grandis]. Zhong yao cai = Zhongyaocai $=$ Journal of Chinese medicinal materials. 2004;27(8):577-8.

2. Nogata $Y$, Sakamoto $K$, Shiratsuchi $H$, Ishii T, Yano M, Ohta H. Flavonoid composition of fruit tissues of citrus species. Biosci Biotechnol Biochem. 2006;70(1):178-92.

3. Li PL, Liu MH, Hu JH, Su WW. Systematic chemical profiling of Citrus grandis 'Tomentosa' by ultrafast liquid chromatography/diode-array detector/quadrupole time-of-flight tandem mass spectrometry. J Pharm Biomed Anal. 2014;90:167-79.

4. Yu J, Wang L, Walzem RL, Miller EG, Pike LM, Patil BS. Antioxidant activity of citrus limonoids, flavonoids, and coumarins. J Agric Food Chem. 2005;53(6):2009-14.

5. Duan L, Guo L, Dou LL, Yu KY, Liu EH, Li P. Comparison of chemical profiling and antioxidant activities of fruits, leaves, branches, and flowers of Citrus grandis 'Tomentosa'. J Agric Food Chem. 2014;62(46):11122-9.

6. Lee MS, Choi J, Posadzki P, Ernst E. Aromatherapy for health care: an overview of systematic reviews. Maturitas. 2012;71(3):257-60.

7. Paradis D, Berail G, Bonmatin JM, Belzunces LP. Sensitive analytical methods for 22 relevant insecticides of 3 chemical families in honey by GC-MS/MS and LC-MS/MS. Analytical bioanalytical chemistry. 2014;406(2):621-33.

8. Hopkins AL. Network pharmacology: the next paradigm in drug discovery. Nature chemical biology. 2008;4(11):682-90.

9. Zhang R, Zhu X, Bai H, Ning K. Network Pharmacology Databases for Traditional Chinese Medicine: Review and Assessment. Front Pharmacol. 2019;10:123.

10. Li S, Fan TP, Jia W, Lu A, Zhang W. Network pharmacology in traditional chinese medicine. Evidencebased complementary alternative medicine: eCAM. 2014;2014:138460.

11. Li S, Zhang B. Traditional Chinese medicine network pharmacology: theory, methodology and application. Chinese journal of natural medicines. 2013;11(2):110-20.

12. Xie Z, Liu Q, Liang Z, Zhao M, Yu X, Yang D, et al. The GC/MS Analysis of Volatile Components Extracted by Different Methods from Exocarpium Citri Grandis. Journal of analytical methods in chemistry. 2013;2013:918406.

13. Gan QX, Wang J, Hu J, Lou GH, Xiong HJ, Peng CY, et al. Modulation of Apoptosis by Plant Polysaccharides for Exerting Anti-Cancer Effects: A Review. Front Pharmacol. 2020;11:792.

14. Perl A. Pathogenesis and spectrum of autoimmunity. Methods in molecular biology. 2012;900:1-9. 
15. Cohen PL, Eisenberg RA. The Ipr and gld genes in systemic autoimmunity: life and death in the Fas lane. Immunol Today. 1992;13(11):427-8.

16. Jiang H, Jayadev S, Lardelli M, Newman M. A Review of the Familial Alzheimer's Disease Locus PRESENILIN 2 and Its Relationship to PRESENILIN 1. Journal of Alzheimer's disease: JAD. 2018;66(4):1323-39.

17. Zhou Y, Zhang W, Easton R, Ray JW, Lampe P, Jiang Z, et al. Presenilin-1 protects against neuronal apoptosis caused by its interacting protein PAG. Neurobiol Dis. 2002;9(2):126-38.

18. Pierce JD, Pierce J, Stremming S, Fakhari M, Clancy RL. The role of apoptosis in respiratory diseases. Clin Nurse Spec. 2007;21(1):22-8. quiz 9-30.

19. Griendling KK, Minieri CA, Ollerenshaw JD, Alexander RW. Angiotensin II stimulates NADH and NADPH oxidase activity in cultured vascular smooth muscle cells. Circ Res. 1994;74(6):1141-8.

20. Pala S, Atilgan R, Kuloglu T, Yalcin E, Kaya N, Etem E. The decrease in hippocampal transient receptor potential M2 (TRPM2) channel and muscarinic acetylcholine receptor 1 (CHRM1) is associated with memory loss in a surgical menopause rat model. Arch Med Sci. 2021;17(1):228-35.

21. Morrow JD, Cho MH, Hersh CP, Pinto-Plata V, Celli B, Marchetti N, et al. DNA methylation profiling in human lung tissue identifies genes associated with COPD. Epigenetics. 2016;11(10):730-9.

22. Maeda Y, Hizawa N, Jinushi E, Honda A, Takahashi D, Fukui Y, et al. Polymorphisms in the muscarinic receptor 1 gene confer susceptibility to asthma in Japanese subjects. Am J Respir Crit Care Med. 2006;174(10):1119-24.

23. Lou XY, Ma JZ, Payne TJ, Beuten J, Crew KM, Li MD. Gene-based analysis suggests association of the nicotinic acetylcholine receptor beta 1 subunit (CHRNB1) and M1 muscarinic acetylcholine receptor (CHRM1) with vulnerability for nicotine dependence. Hum Genet. 2006;120(3):381-9.

24. Khan R, Sultana S. Farnesol attenuates 1,2-dimethylhydrazine induced oxidative stress, inflammation and apoptotic responses in the colon of Wistar rats. Chem-Biol Interact. 2011;192(3):193-200.

25. Delmondes GD, Bezerra DS, Dias DD, Borges AD, Araujo IM, da Cunha GL, et al. Toxicological and pharmacologic effects of farnesol (C15H260): A descriptive systematic review. Food Chem Toxicol. 2019;129:169-200.

26. Keiser MJ, Roth BL, Armbruster BN, Ernsberger P, Irwin JJ, Shoichet BK. Relating protein pharmacology by ligand chemistry. Nature biotechnology. 2007;25(2):197-206.

27. Smoot ME, Ono K, Ruscheinski J, Wang PL, Ideker T. Cytoscape 2.8: new features for data integration and network visualization. Bioinformatics. 2011;27(3):431-2.

28. Scardoni G, Tosadori G, Faizan M, Spoto F, Fabbri F, Laudanna C. Biological network analysis with CentiScaPe: centralities and experimental dataset integration. F1000Research. 2014;3:139.

29. Nawrocki MJ, Perek B, Sujka-Kordowska P, Konwerska A, Kaluzna S, Zawierucha P, et al. Differences in Expression of Genes Involved in Bone Development and Morphogenesis in the Walls of Internal Thoracic Artery and Saphenous Vein Conduits May Provide Markers Useful for Evaluation Graft Patency. International journal of molecular sciences. 2019;20(19). 
30. Barabasi AL, Oltvai ZN. Network biology: understanding the cell's functional organization. Nat Rev Genet. 2004;5(2):101-13.

31. Liao Y, Wang J, Jaehnig EJ, Shi Z, Zhang B. WebGestalt 2019: gene set analysis toolkit with revamped Uls and APIs. Nucleic acids research. 2019;47(W1):W199-205.

32. Wang Y, Zhang S, Li F, Zhou Y, Zhang Y, Wang Z, et al. Therapeutic target database 2020: enriched resource for facilitating research and early development of targeted therapeutics. Nucleic acids research. 2020;48(D1):D1031-D41.

\section{Figures}

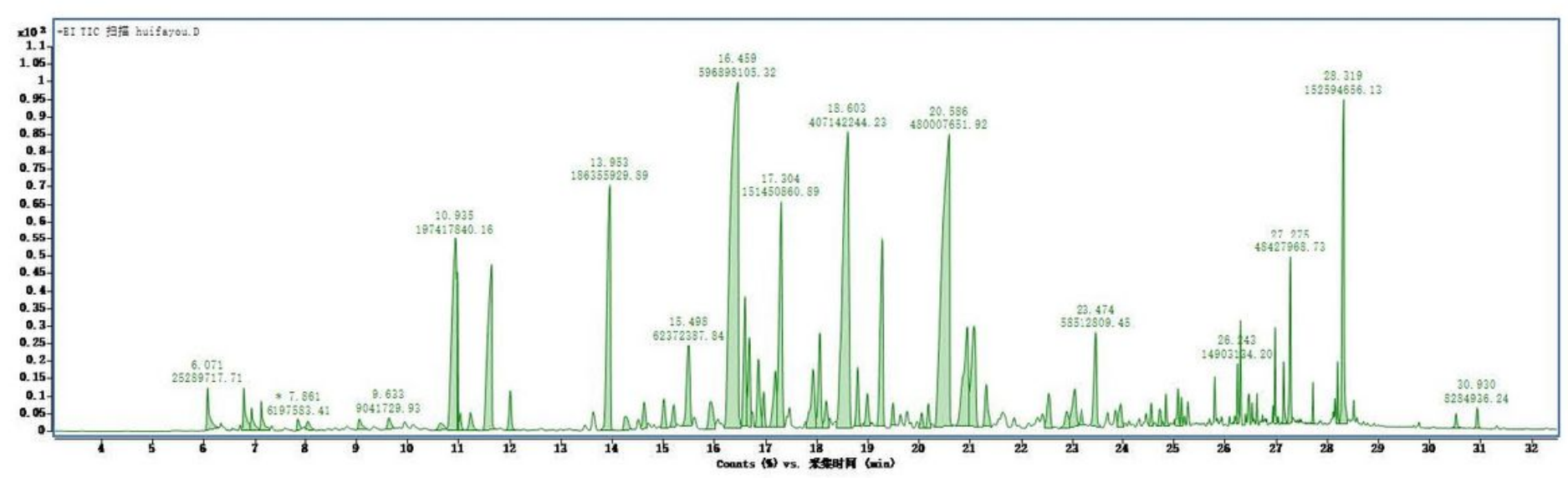

Figure 1

A total ion chromatogram of essential oil from leaves of C. grandis 'Tomentosa'. 


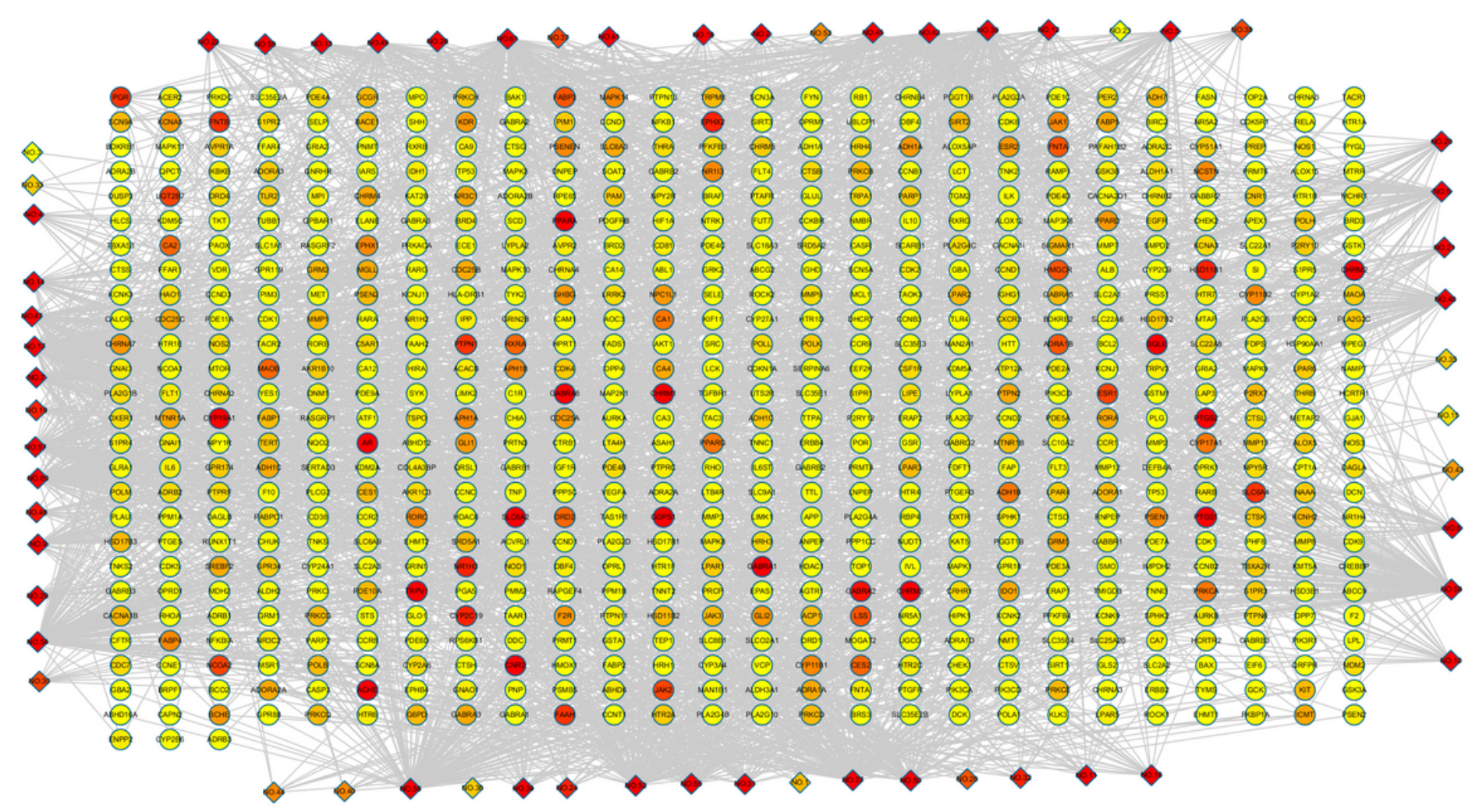

Figure 2

The component-target network of essential oil composition. The diamond nodes represent ingredients, and the circular nodes represent targets. The colors of the nodes are illustrated from red to yellow in descending order of degree values. 


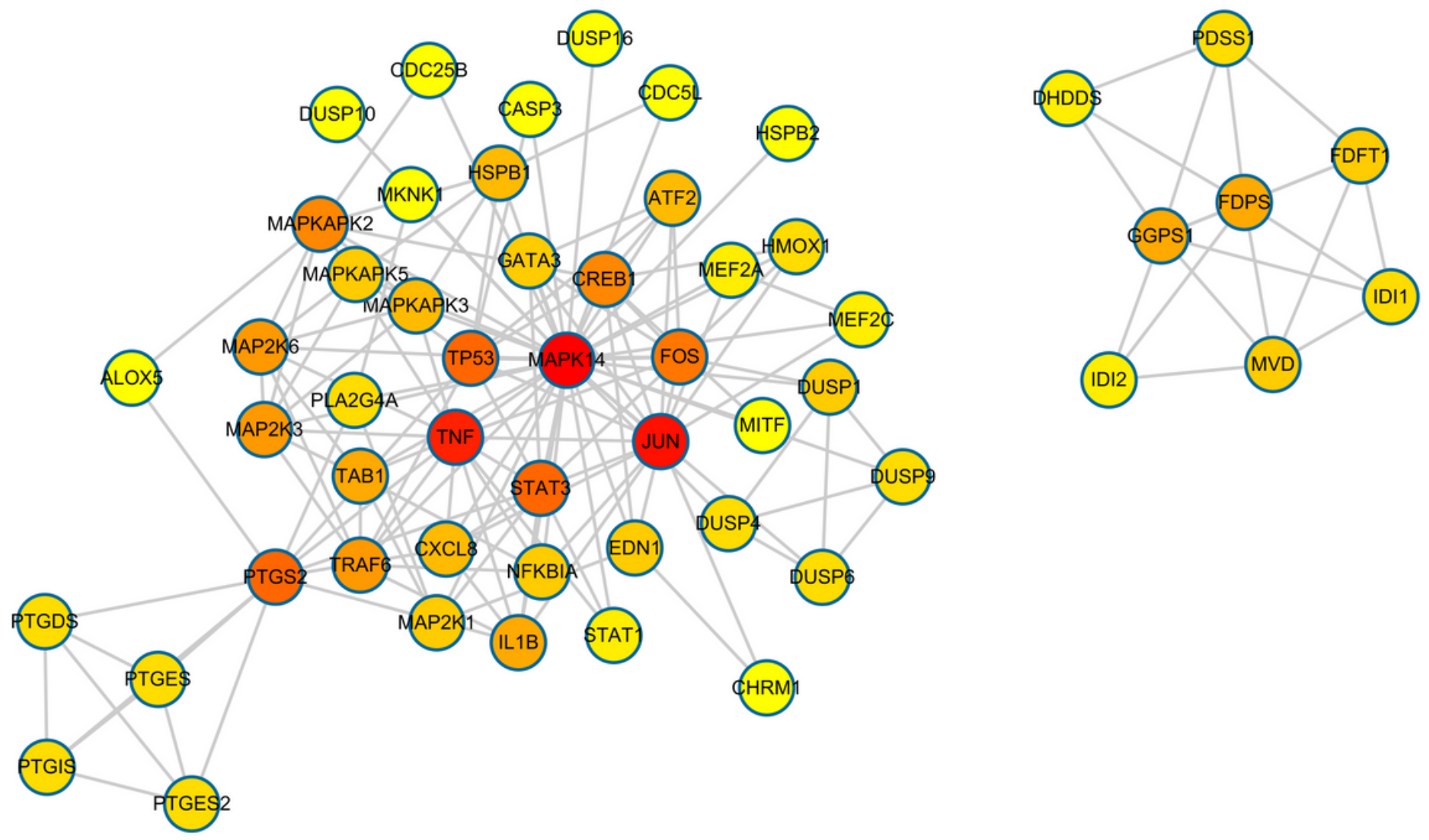

Figure 3

Protein-protein interaction network for essential oil composition. The colors of the nodes are illustrated from red to yellow in descending order of degree values.

Bar chart of Biological Process categories

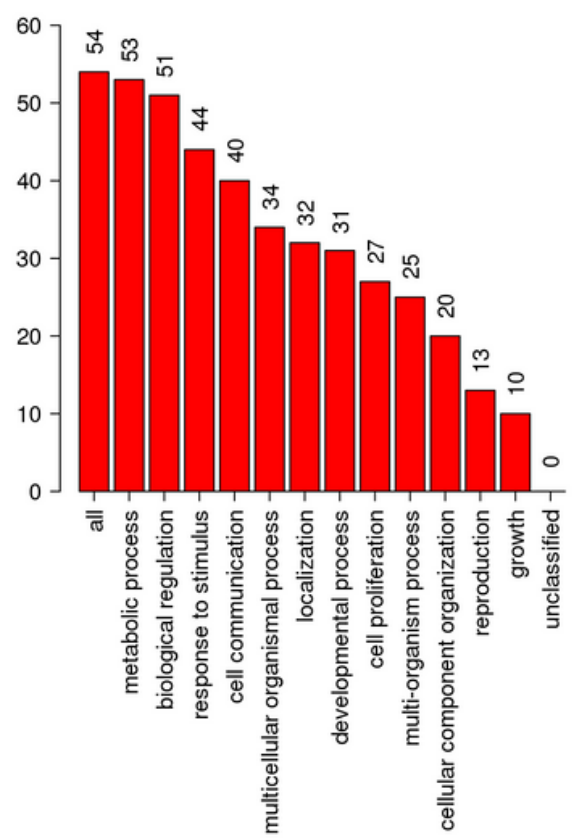

(A)
Bar chart of Cellular Component categories

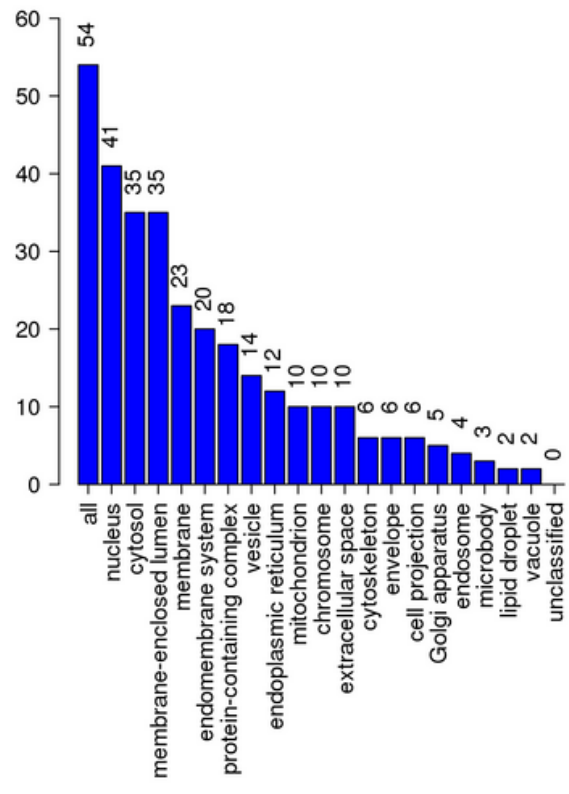

(B)
Bar chart of Molecular Function categories

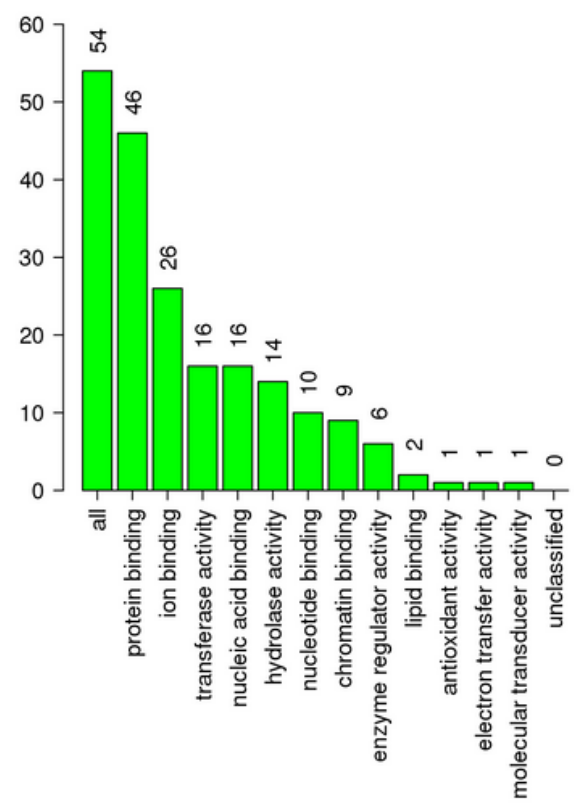

(C) 
Figure 4

GO enrichment analyses of target proteins. (A) biologic process, (B) cellular component, (C) molecular functions.

$=F \mathrm{FD} \leq 0.05 \quad[\mathrm{FDR}>0.05$

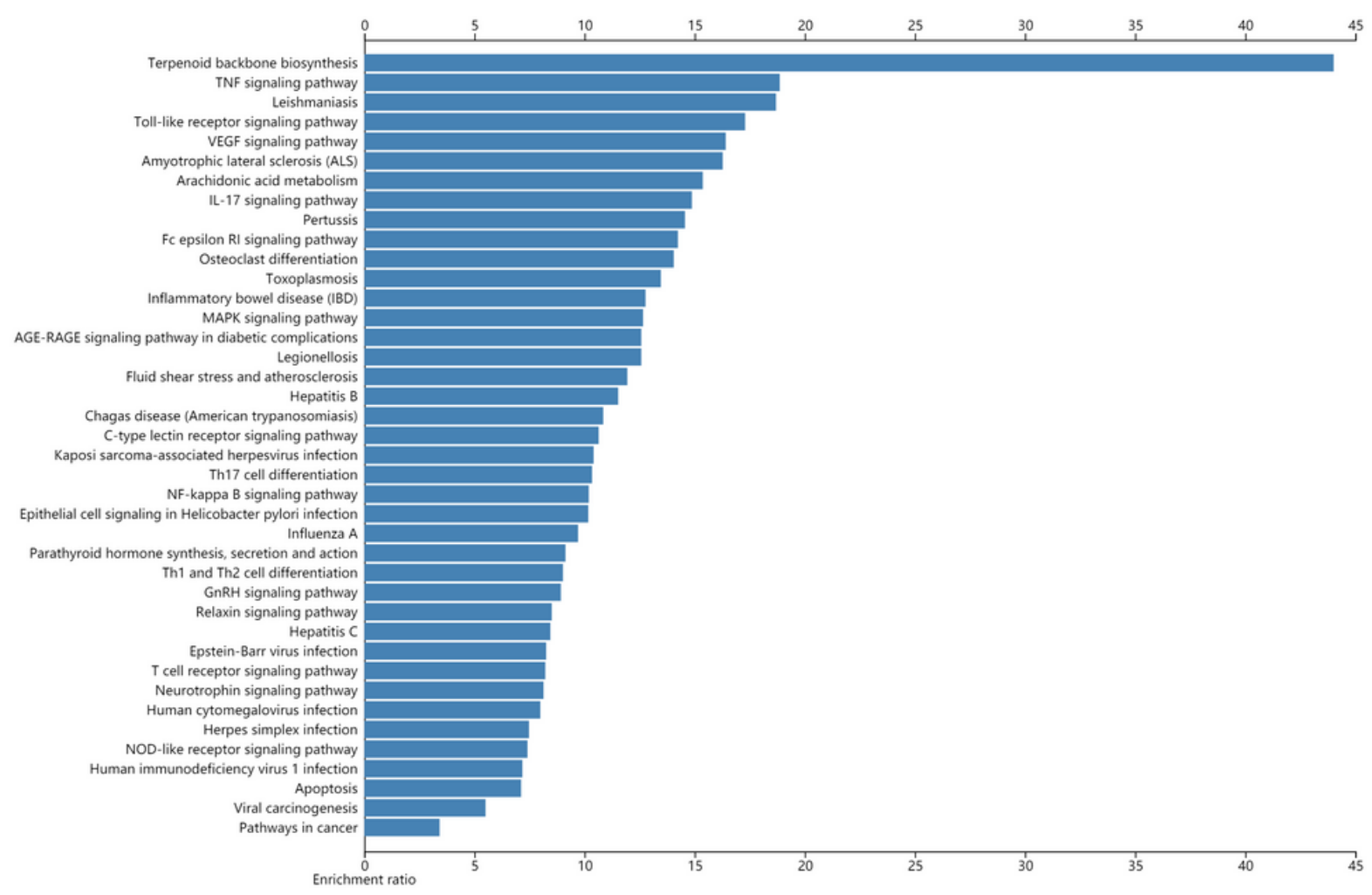

Figure 5

Enriched KEGG pathway of potential targets. 


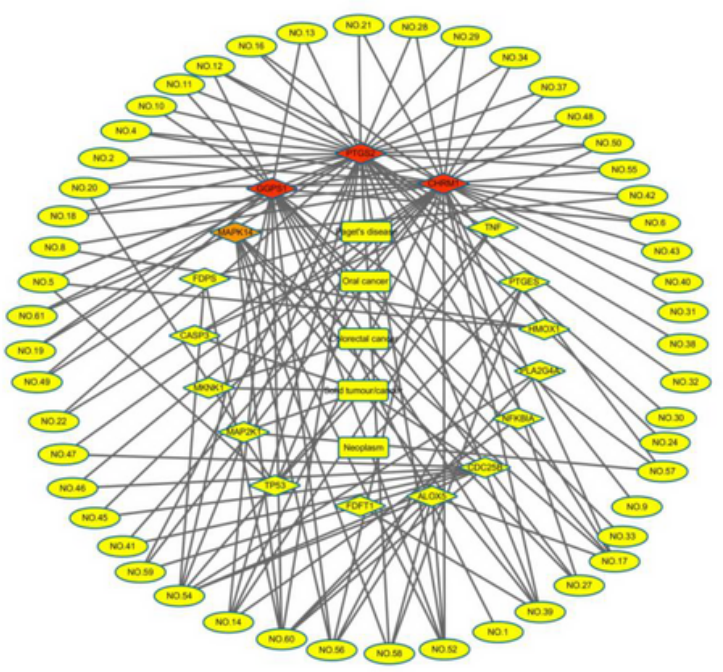

(A)

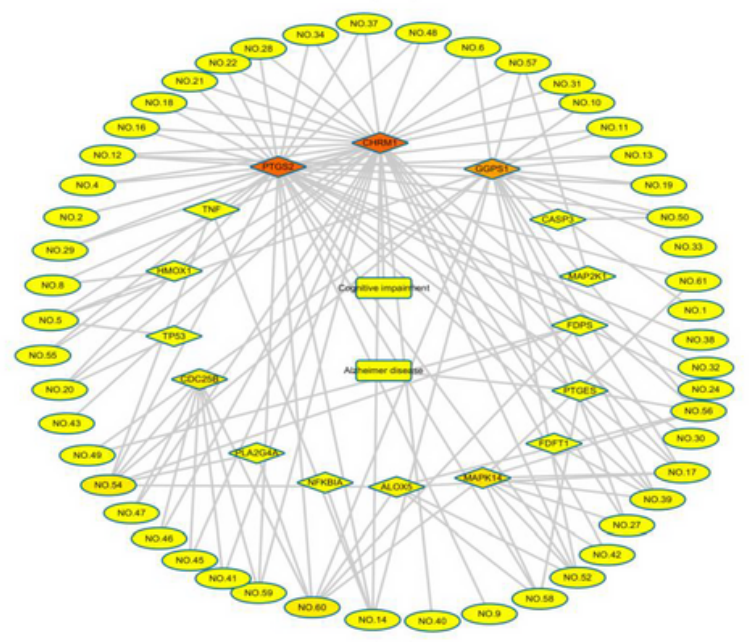

(C)

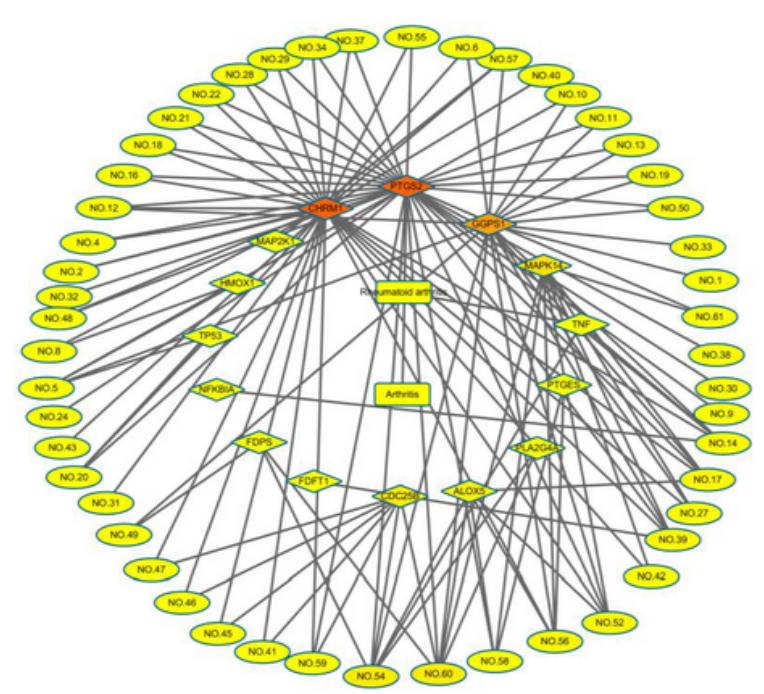

(B)

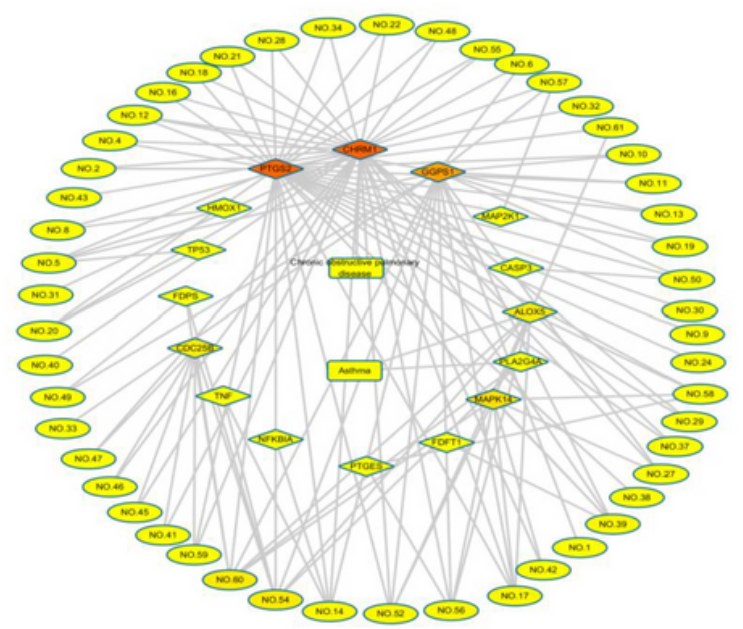

(D)

\section{Figure 6}

The component-target-disease networks. (A) component-target-tumor network, (B) component-targetimmune disease network, (C) component-target-neurodegenerative disease network, (D) componenttarget-respiratory network. The diamond nodes represent ingredients, the circular nodes represent targets, and the rectangle represent diseases. The colors of the nodes are illustrated from red to yellow in descending order of degree values. 


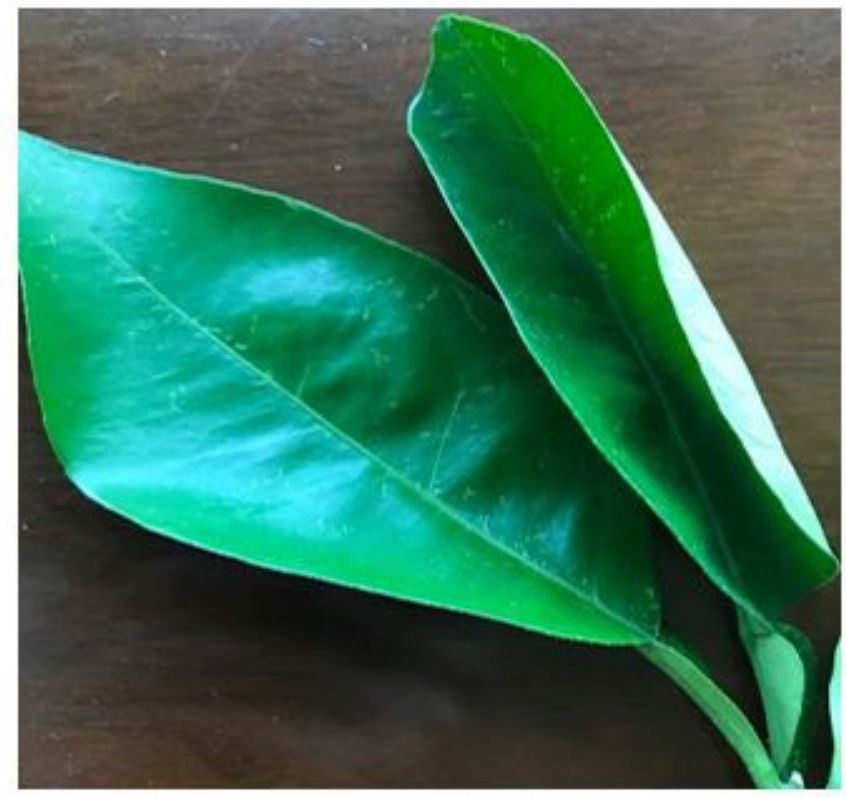

A

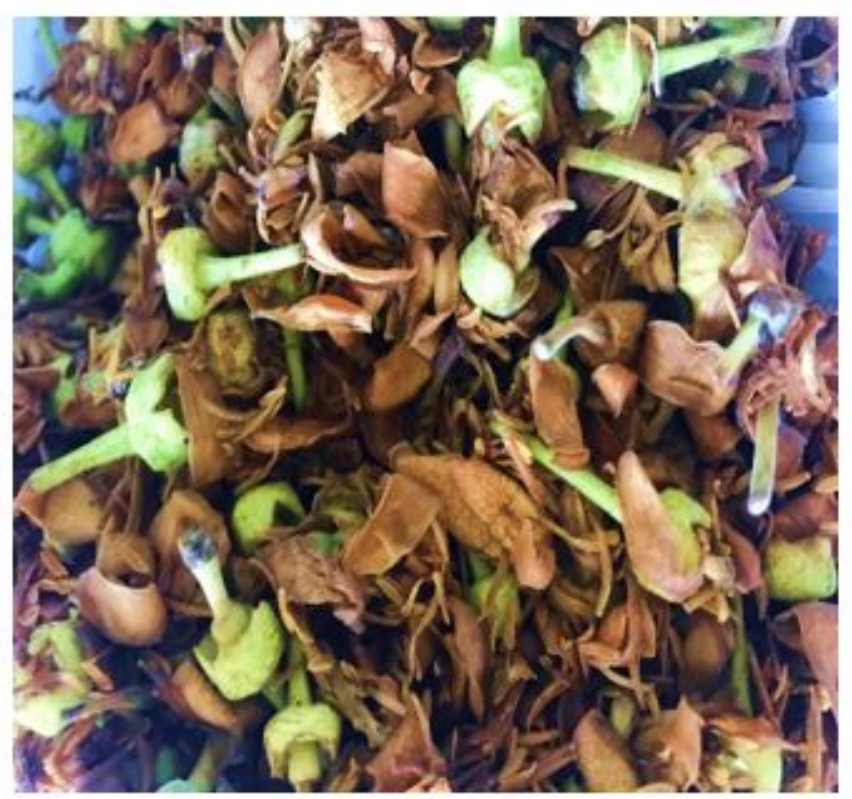

B

\section{Figure 7}

Leaves (A) and flowers (B) of C. grandis 'Tomentosa'

\section{Supplementary Files}

This is a list of supplementary files associated with this preprint. Click to download.

- Supplementaryfile.docx 